\title{
Four Cousins with Hypospadias, Is It Familial or Environmental? (Case Report)
}

\author{
Mohamed Elsayed Mohamed Mohamed ${ }^{*}(\mathbb{B}$, Mina Senada, Mohamed Ahmed Hassan, \\ Yousef Abdalazeem
}

Plastic Surgery Department, Ahmed Maher Teaching Hospital, Cairo, Egypt

Email: ^Mghabn5777@yahoo.com, ^m.elsayed.tajmeel@gothi.cloud.gov.eg

How to cite this paper: Mohamed, M.E.M., Senada, M., Hassan, M.A. and Abdalazeem, Y. (2019) Four Cousins with Hypospadias, Is It Familial or Environmental? (Case Report). Modern Plastic Surgery, 9, 59-63. https://doi.org/10.4236/mps.2019.93008

Received: May 30, 2019

Accepted: July 28, 2019

Published: July 31, 2019

Copyright () 2019 by author(s) and Scientific Research Publishing Inc. This work is licensed under the Creative Commons Attribution International License (CC BY 4.0).

http://creativecommons.org/licenses/by/4.0/ (c) (i) Open Access

\begin{abstract}
Hypospadias is one of the most common birth defects. However, its etiology remains largely unknown. Genetic and also intrauterine environmental factors have a principal role in causing familial hypospadias. Hypospadias repair is done through several techniques, one of which is Snodgrass technique which has many advantages. The 4 cousins underwent repair with no complications during 6 months follow up period. Methods: Urethroplasty using Snodgrass hypospadias repair of 4 cousins with positive parental consanguinity and absent family history of hypospadias. Results: 4 cousins underwent Snodgrass (Tubularized incised plate urethroplasty) with no complications after 6 months follow up. Conclusion: Although there is high heritability of hypospadias that also aggregates within second- and third-degree relatives, environmental factors may play a principal role in causing familial hypospadias. Hypospadias repair has a long learning curve. The continuous auditing should be done to improve the results.
\end{abstract}

\section{Keywords}

Hypospadias, Familial, Environmental, Snodgrass Repair

\section{Introduction}

Hypospadias is the most common congenital abnormality affecting the male urethra, with a worldwide incidence of about 1:300 live male births. Hypospadias is the abnormal location of the urethra on the ventral surface of the penis [1] [2].

The etiology of hypospadias in the majority of cases remains unknown. There is a genetic background for hypospadias through studying and observing genetic syndromes associated with hypospadias, genetic defects in the biosynthesis and function of Androgen and the mood of monogenic inheritance in families with 
hypospadias [3] [4] [5] [6].

However, fewer than 5 percent of all cases of hypospadias may be associated with such conditions. In addition to a family history of hypospadias, only a few risk factors associated with hypospadias have been found, for example, paternal subfertility and intrauterine growth retardation [7] [8] [9].

The goal of hypospadias repair is to create a straight penis with a slit-like meatus at the tip of the glans and a urethra of uniform caliber and adequate length, reconstructing a symmetrical glans and penile shaft and achieving projectile stream and normal erection [10].

\section{Case Report}

Four cousin children were presented to our outpatient clinic, complaining of dribbling of urine and inability to pass a forward urine stream.

From history, there is positive consanguinity as their parents were 2 sisters (with a history of parental consanguinity) married to 2 brothers. No family history of similar conditions, nor medication history during pregnancy (See Table 1).

The first parents have 5 sons, 2 of them were with hypospadias; the first child was 10 years old, with distal penile hypospadias, his brother was 2.5 years old with sub-coronal hypospadias.

The second parents have 7 children, 3 of them are boys, 2 with hypospadias; the first boy was 9 years old with sub-coronal hypospadias. His brother was 2.5 years old with glanular hypospadias.

The 4 children underwent Snodgrass repair, in 3 of them we used preputial flap and the 4th one Dartos flap as a second intervening layer.

Post-operative hospital stay was 10 days, Catheter removed before discharge, urethral dilatation started immediately with frequency of once daily for the first week, then once weekly for the ${ }_{\text {next }}$ month. Follow up was done once weekly. There were no complications for 6 months follow up (See Cases 1-4).

Table 1. Showing patient data and procedures done.

\begin{tabular}{ccccc}
\hline & Patient (1) & Patient (2) & Patient (3) & Patient (4) \\
\hline Age & 10 years & 2.5 years & 9 years & 2.5 years \\
\hline Relationship & \multicolumn{2}{c}{ Brothers } & Brothers \\
Diagnosis & Distal penile & Sub-coronal & Sub-coronal & Glanular \\
Chordee & Absent & Absent & Absent & Absent \\
Prepuce & Incomplete & Incomplete & Incomplete & Incomplete \\
Associated anomalies & Not present & Not present & Not present & Not present \\
Shape of the scrotum & Normal & Normal & Normal & Normal \\
Flap (Second layer) & Preputial & Preputial & Preputial & Dartos \\
Complications & UTI (treated) & - ------ & ------ & -----
\end{tabular}



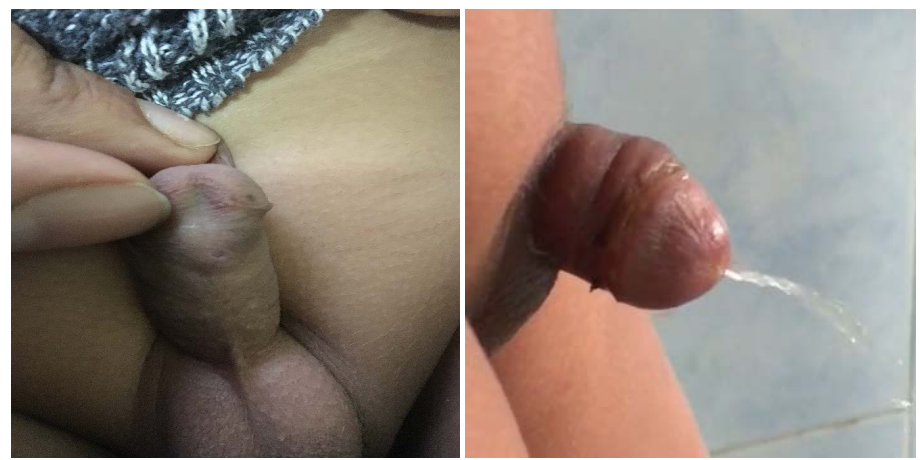

Case 1. Distal penile pre- and post-operative photos.
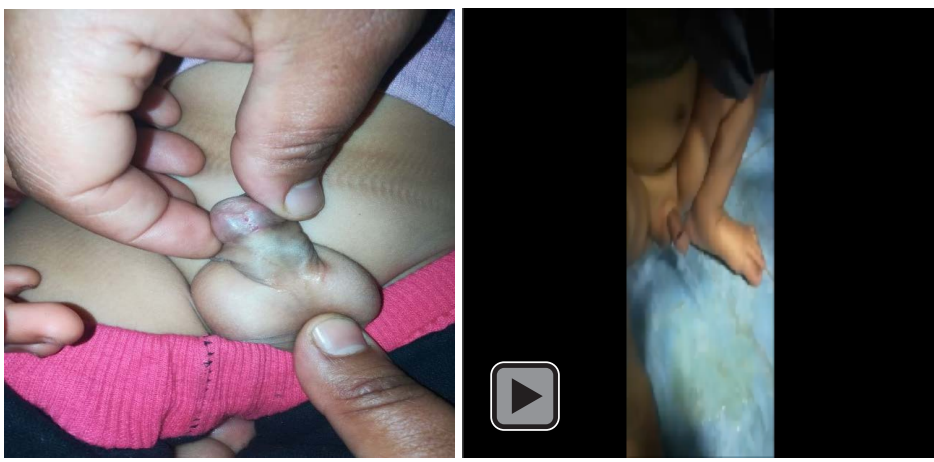

Case 2. Sub-coronal hypospadias pre-operative photo and post-operative video.

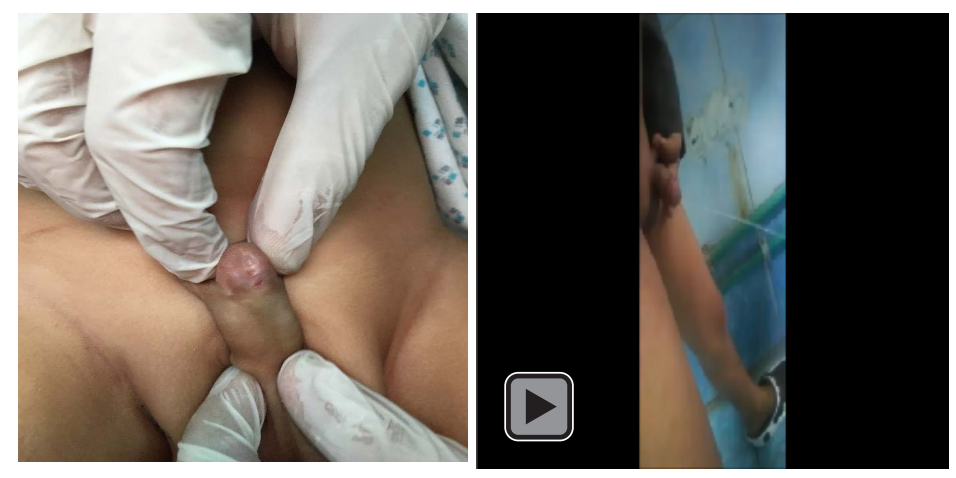

Case 3. Sub-coronal hypospadias pre- and post-operative photos and video.

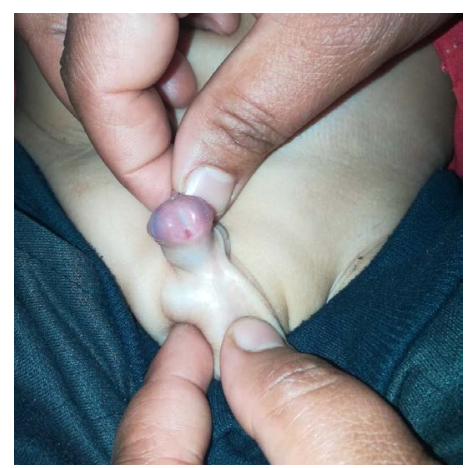

Case 4. Glanular hypospadias. 


\section{Discussion}

The inheritance appears to be transmitted equally through the paternal and maternal sides of a family. In studies of twin pairs, Kallen et al. [11] found a concordance rate of 18 percent, whereas another study reported concordance rates of 9 percent and 27 percent for dizygotic and monozygotic twins, respectively [12].

Brothers of a hypospadias case have, in smaller descriptive or case-control studies, been estimated to have about a 9 percent chance of developing hypospadias. It was found that the more severe the hypospadias in an individual, the higher the incidence in first-degree relatives, ranging from 3.5 percent to 16.7 percent [13].

It was found that hypospadias in second- and third-degree relatives was inherited equally from the maternal and the paternal sides. It has previously been hypothesized that hypospadias is one symptom of the testicular dysgenesis syndrome, which may be increasingly common because of adverse environmental influences, for example, estrogenic or anti-androgenic substances [14].

Here, consanguinity might be a cause of familial hypospadias and it was apparent in the second-generation members without previous history of similar conditions, so parents were notified with the increased risk of having grandsons with hypospadias and good prenatal care was advised in the future.

\section{Conclusion}

Although there is high heritability of hypospadias that also aggregates within the second and third-degree relatives, environmental factors may play a principal role in causing familial hypospadias.

Hypospadias repair has a long learning curve. The continuous auditing should be done to improve the results.

\section{Conflicts of Interest}

The authors declare no conflicts of interest regarding the publication of this paper.

\section{References}

[1] Djakovic, N., Nyarangi-Dix, J., Ozturk, A. and Hohenfellner, M. (2008) Hypospadias. Advances in Urology, 2008, Article ID: 650135. https://doi.org/10.1155/2008/650135

[2] Iqbal, T., Nasir, U., Khan, M., et al. (2011) Frequency of Complication in the Snodgrass Repair and Its Risk Factors. Pakistan Journal of Surgery, 27, 188-193.

[3] Baskin, L.S. and Ebbers, M.B. (2006) Hypospadias: Anatomy, Etiology, and Technique. Journal of Pediatric Surgery, 41, 463-472. https://doi.org/10.1016/j.jpedsurg.2005.11.059

[4] Manson, J.M. and Carr, M.C. (2003) Molecular Epidemiology of Hypospadias: Review of Genetic and Environmental Risk Factors. Birth Defects Research Part A: Clinical and Molecular Teratology, 67, 825-836. https://doi.org/10.1002/bdra.10084 
[5] Thai, H.T., Kalbasi, M., Lagerstedt, K., et al. (2005) The Valine Allele of the V89L Polymorphism in the 5- $\alpha$-Reductase Gene Confers a Reduced Risk for Hypospadias. The Journal of Clinical Endocrinology \& Metabolism, 90, 6695-6698. https://doi.org/10.1210/jc.2005-0446

[6] Kim, K.S., Liu, W., Cunha, G.R., et al. (2002) Expression of the Androgen Receptor and $5 \alpha$-Reductase Type 2 in the Developing Human Fetal Penis and Urethra. Cell and Tissue Research, 307, 145-153. https://doi.org/10.1007/s004410100464

[7] Wennerholm, U.B., Bergh, C., Hamberger, L., et al. (2000) Incidence of Congenital Malformations in Children Born after ICSI. Human Reproduction, 15, 944-948. https://doi.org/10.1093/humrep/15.4.944

[8] Gatti, J.M., Kirsch, A.J., Troyer, W.A., et al. (2001) Increased Incidence of Hypospadias in Small-for-Gestational Age Infants in a Neonatal Intensive-Care Unit. BJU International, 87, 548-550. https://doi.org/10.1046/j.1464-410X.2001.00088.x

[9] Hussain, N., Chaghtai, A., Herndon, C.D., et al. (2002) Hypospadias and Early Gestation Growth Restriction in Infants. Pediatrics, 109, 473-478. https://doi.org/10.1542/peds.109.3.473

[10] Bhat, A. (2008) General Considerations in Hypospadias Surgery. Indian Journal of Urology, 24, 188-194. https://doi.org/10.4103/0970-1591.40614

[11] Kallen, B., Castilla, E.E., Robert, E., et al. (1992) An International Case Control Study on Hypospadias. The Problem with Variability and the Beauty of Diversity. European Journal of Epidemiology, 8, 256-263. https://doi.org/10.1007/BF00144810

[12] Fredell, L., Kockum, I., Hansson, E., et al. (2002) Heredity of Hypospadias and the Significance of Low Birth Weight. Journal of Urology, 167, 1423-1427. https://doi.org/10.1016/S0022-5347(05)65334-7

[13] Sharpe, R.M. (2003) The 'Oestrogen Hypothesis'-Where Do We Stand Now? International Journal of Andrology, 26, 2-15. https://doi.org/10.1046/j.1365-2605.2003.00367.x

[14] Sharpe, R.M. (2006) Pathways of Endocrine Disruption during Male Sexual Differentiation and Masculinisation. Best Practice \& Research Clinical Endocrinology \& Metabolism, 20, 91-110. https://doi.org/10.1016/j.beem.2005.09.005 